\title{
A ORIGEM E A CONSTITUIÇÃO ATUAL DOS CENTROS COMERCIAIS DE CAMPINA GRANDE - PB
}

Péricles Alves Batista ${ }^{1}$

\begin{abstract}
Resumo
O presente artigo tem por objetivo analisar a reestruturação do comércio de Campina Grande Paraíba, localizada no Nordeste brasileiro. O texto aborda a respeito da origem e a constituição dos centros comerciais da área central da cidade, sobretudo, a partir das mudanças ocorridas no setor terciário. Com a recente ascensão desse setor na economia urbana, alguns pequenos centros de comércio emergiram e vem alterando oespaço urbano local. Como metodologia, utilizou-se pesquisa documental em arquivos de jornais para a obtenção de informações desses empreendimentos na última década. Isso nos leva a afirmar que o processo de descentralização pelo qual a área central passa, apresenta uma continuidade cada vez mais evidente, mas, contraditoriamente, ao mesmo tempo, reforça a centralidade do centro de Campina Grande. Sendo assim, observou-se um processo de descentralização do comércio local para além da área central, impulsionado pela expansão da cidade na direção Leste, em consonância com a localização de novos empreendimentos comerciais, a exemplo do shopping center.
\end{abstract}

Palavras-chave: Centros Comerciais; Descentralização; Reestruturação Urbana; Shopping Center.

\section{THE ORIGIN AND CONSTITUTION OF COMMERCIAL CENTRES IN CAMPINA GRANDE- PB}

\begin{abstract}
This article aims to analyze the restructuring of commercial areas in the city Campina Grande - Paraíba, that is located in northeastern of Brazil. The present discussion is about the origin and the establishment of shopping centers in the central area of this city and the changes that happened in the local service sector in the last years. Considering the recent rise of the service sector in the urban economy, some small shopping centers emerged and they're changing the local urban space. The methodology used was a documentary research in newspaper archives that contains information from these developments in the last decade. The result shows that the decentralization process of service sector areas is continuous, but, paradoxically, it reinforces the centrality of the commercial center of Campina Grande - PB. Thus, there are a specific local trade decentralization process, driven by the expansion of the city east areas and the location of new businesses, such as a shopping center.
\end{abstract}

Keywords: Shopping centers; decentralization; Urban restructuring.

\footnotetext{
${ }^{1}$ Licenciado em Geografia pela Universidade Estadual da Paraíba (UEPB).Mestre em Geografia pela Universidade Federal da Paraíba (UFPB). Doutorando em Geografia pela Universidade Federal do Rio Grande do Norte (UFRN). Membro da Rede de Pesquisadores sobre Cidades Médias (ReCiMe). Atuacomo Professor da Educação Básica da Prefeitura Municipal de Pocinhos - PBe Professor na Escola Superior de Aviação Civil em Campina Grande - PB. Email: pericles_batista@yahoo.com.br.
}

Sociedade e Território - Natal. Vol. 28, N. 2, p. 136 - 152. Jun./Dez. de 2016 


\section{L'ORIGINE ET LA CONSTITUTION ACTUEL DES CENTRES COMMERCIAUX DE CAMPINA GRANDE - PB}

\section{Résumé}

Cet article vise à analyser la restructuration du commerce de Campina Grande - Paraíba, situé dans le nord du Brésil. Le texte porte sur l'origine et la mise en place de centres commerciaux dans la zone centrale de la ville, principalement des changements dans le secteur tertiaire. Avec la hausse récente de ce secteur dans l'économie urbaine, certains petits centres commerciaux ont émergé et sont en train de changer l'espace urbain local. La méthodologie utilisée est la recherche documentaire dans les archives de journaux pour obtenir des informations à partir de ces développements dans la dernière décennie. Cela nous amène à affirmer que le processus de décentralisation par lequel la zone centrale va, présente une continuité de plus en plus évidente, mais contradictoire en même temps, renforce la centralité du centre de Campina Grande. Ainsi, il y avait un processus de décentralisation du commerce local au-delà de la zone centrale, stimulée par l'expansion de la ville vers l'est, en accord avec l'emplacement des nouvelles entreprises, comme le centre commercial.

Mots-clés: Centres commerciaux; la décentralisation; Restructuration urbaine.

\section{INTRODUÇÃO}

O presente trabalho é parte da nossa dissertação de mestrado intitulada "OBoulevard Shoppinge a formação de uma nova Centralidade em Campina Grande-PB”, desenvolvida entre 2009 a 2011, no Programa de Pós-Graduação em Geografia(PPGG) da Universidade Federal da Paraíba. A pesquisa teve como objetivo geral analisar as modificações/reestruturações do espaço urbano campinense ocorridas na última década, nas adjacências do Shopping Boulevard. Dessa forma, o presente texto analisa especificamente a origem e a constituição dos principais centros comerciais da Área Central de Campina Grande, sobretudo a partir das recentes mundanças ocorridas no seu setor terciário.

Com a ascensão do setor terciário na economia urbana, alguns pequenos centros comérciais emergiram na Área Central, e a partir daí, vem reestruturando o seu comércio, bem como o próprio espaço urbano de Campina Grande.Nesse contexto, nos chamou a atenção que esses centros de comércio existentes, apesar de seu pequeno porte, acabaram na maioria das vezes ganhando a denominação de "shopping centers".Na verdade, a maioria desses pequenos centros de comércio poderia muito bem ser classificados como galerias e não propriamente de "shoppings".

Por entendermos que a cidade de Campina Grande apresenta uma importância significativa no interior da Região Nordeste, e mais ainda, para o estado da Paraíba, é que 
buscamos entender algumas das características do seu comércio, bem como as recentes mundanças intraurbanas, principalmente o fenômeno da formação de novas áreas de centralidade que ocorre na cidade.

Como procedimento metodológico, houve a pesquisa documental em arquivos de jornais para a obtenção de informações do período que antecedeu a construção dos empreendimentos comerciais estudados. Realizou-seainda entrevistas com alguns antigos comerciantes da Área Central.

Ao abordar a questão do shopping center, inclusive, tecendo considerações importantes sobre a localização espacial desses centros de comércio no território brasileiro, faremos em primeiro lugar uma análise bibliográfica geral sobre a temática. Em seguida, trataremos de forma específica sobre o comércio campinense, procurando ao final deste trabalho tercer algumas consideraçõessobre a origem e constituição dos centros comerciais da Àrea Central de Campina Grande.

\section{O SHOPPING CENTER NO BRASIL E EM CAMPINA GRANDE}

Para iniciar a temática intitulada, é necessário esclarecer duas questões: em primeiro lugar, trataremos de modo geral a respeito do shopping center no Brasil, principalmente no que diz respeito à sua implantação, localização e características próprias dentro do território brasileiro. E, em segundo lugar, de maneira específica, apresentaremos o shopping center em Campina Grande.

Dessa maneira, para iniciar a discussão sobre o tema "shopping center" no Brasil, destacamos, dentro da literatura geográfica brasileira, a contribuição da professora Silvana Maria Pintaudi, a partir dos estudos que renderam sua tese de doutorado, em 1989, intitulada “O Templo da Mercadoria - estudo sobre os Shopping-Centers do Estado de São Paulo”. Essa obra é considerada ainda hoje por autores de diferentes áreas do conhecimento como referência básica para quem deseja entender as questões geográficas relacionadas aoshopping center no Brasil.

Sendo assim, além de fazermos menção a essa e outras publicações de Pintaudi (1989, 1992 e 1999), usaremos outras referências que, de alguma forma, contribuíram com a temática; destacamos: Hirschfeldt (1986), Meyer (1993), Villaça (1998), Santos \& Silveira (2001), Souza (2003) e Padilha (2006). 
No Brasil, o primeiro shopping center foi construído no estado de São Paulo, no ano de 1966 (HIRSCHFELDT, 1986; PINTAUDI, 1992; MEYER, 1993 e PADILHA, 2006). A partir de então, o setor brasileiro de shopping centers, apresentou, década após década, uma crescente ascensão. De acordo com Meyer (1993), o Shopping Center Iguatemi, o primeiro a ser instalado na capital paulista, foi construído na Avenida Brigadeiro Faria Lima ${ }^{2}$.Sobre as modificações ocorridas nessa avenida, Pintaudi (1992, p. 35) afirma que com:

[...] a implantação do Shopping Center Iguatemi, iniciou-se uma nova etapa de valorização do espaço na sua vizinhança. Quem teve a oportunidade de conhecer a Avenida Brigadeiro Faria Lima, onde esse SC se situa, na década de 60, quando ainda se chamava Rua Iguatemi, e a vê hoje, sabe bem a diferença. [...] Hoje isso está totalmente mudado, e essa transformação ocorre após a implantação do SC. Além de terem sido feitas desapropriações, para que a circulação de automóveis fosse melhorada, as antigas moradias foram sendo paulatinamente substituídas por bancos, edifícios de escritórios (alguns de residências) e lojas comerciais e de serviços.

Diferentemente dos shopping centers dos Estados Unidos, que geralmente eram construídos longe dos centros das cidades, o Shopping Iguatemi, contrariando essa lógica, foi construído dentro da própria cidade de São Paulo e, mais ainda, esse estabelecimento se localiza com certa proximidade em relação ao centro. Ainda sobre esse shopping center, Pintaudi (1999, p. 153) afirma que "não surgiu como uma solução para o equipamento comercial, mas muito mais como uma novidade [...]". Vale notar que o período em que se deu a inauguração coincide com o momento do aumento significativo do número de veículos que passavam a alterar radicalmente o uso das ruas da cidade de São Paulo.

Outra comparação em relação aos shopping centers dos Estados Unidos e do Brasil, sobretudo no que diz respeito ao ponto de vista quantitativo, percebe-se a imensa diferença existente entre os dois países. Só para ter uma amostra da desproporção dos números entre esses dois países no mesmo período, tomaremos por base dados apresentados por alguns autores que desenvolveram trabalhos sobre a temática "shopping center".

No caso dos Estados Unidos, se compararmos com o mesmo período em relação ao Brasil (década de 1960 e 1970), Padilha (1996, p. 60) afirma que o número de shoppings nos EUA na década de 1960 era de 3.700 unidades. Dez anos depois, mais de oito mil shoppings foram inaugurados em território norte-americano.

\footnotetext{
${ }^{2}$ Para entender mais sobre o conjunto de transformações urbanas que a Avenida Brigadeiro Faria Lima passou, ver também: Carlos (2001, p. 45 - 84).
} 
Como já afirmamos, o primeiro shopping center do Brasil foi instalado em 1966. Depois desse marco, somente dez anos depois é que apareceu o segundo shopping na capital paulista (PINTAUDI, 1999, p.153), o Continental, localizado na divisa entre São Paulo e Osasco, que nas palavras de Villaça (1998, p. 302), "foi um fracasso, visto ter sido uma temeridade, naquela época (início da década de 1970) localizar um shopping num subúrbio de classe média e média baixa".

No "final de 1971 é inaugurado o segundo S.C. brasileiro, o Conjunto Nacional Brasília” (HIRSCHFELDT, 1986, p. 24). Depois desse empreendimento no Centro-Oeste, surge no estado do Paraná o terceiro shopping center a ser implantado no país. "Entre 1975 e 1979 foram inaugurados mais quatro SC (dois em São Paulo, um em Minas Gerais e um na Bahia)" (PINTAUDI,1992, p. 17).

Santos \& Silveira (2001, p. 152) explicam que a expansão do número de shopping centers no Brasil é um fenômeno recente. Dessa maneira, pode-se afirmar que a localização espacial desse tipo de atividade comercial mudou muito nos últimos tempos, assim como aumentou o número de unidades em cidades médias.

De acordo com Souza (2003, p. 65), “a partir de década de 80, se estabelece solidamente e começa a proliferar um outro símbolo da descentralização das atividades terciárias, o shopping center.'Tanto Hirschfeldt (1986) como Pintaldi (1992) concordam que o marco desse fenômeno no Brasil ocorre a partir de 1980.

Atualmente, segundo dados da $\mathrm{ABRASCE}^{3}$, em 2004 havia 325 shopping centersem operação no Brasil, com 40.803 lojas, 6,2 milhões de $\mathrm{m}^{2}$ e com uma estimativa de frequência da ordem de 185 milhões de pessoas por mês.Assim, nota-se recentemente como foi rápida a expansão deste tipo de empreendimento no Brasil, pois em apenas seis anos (2004-2010), o número de shopping centers aumentou em 83 unidades. Os dados do gráfico da ABRASCE, abaixo, mostram a evolução em unidades, do ano 2005 até 2010. (Grafico 01). Até o presente ano de 2016, são 549 unidades de shopping centers no Brasil, segundo dados dessa associação ${ }^{4}$.

\footnotetext{
3 Sigla que significa: Associação Brasileira dos Shopping Centers. Dados disponíveis em: http://www.portaldoshopping.com.br. Acesso em 18/05/2009 e 23/06/2011.

${ }^{4}$ Dados disponíveis em: http://www.portaldoshopping.com.br/monitoramento/numeros-do-setor. Acesso em 30/08/2016.
} 
Assim, nota-se como foi rápida a expansão deste tipo de empreendimento pelo Brasil, pois, na pesquisa realizada por Hirschfeldt (1986), no ano de 1986 havia somente 31 shopping centersno Brasil.

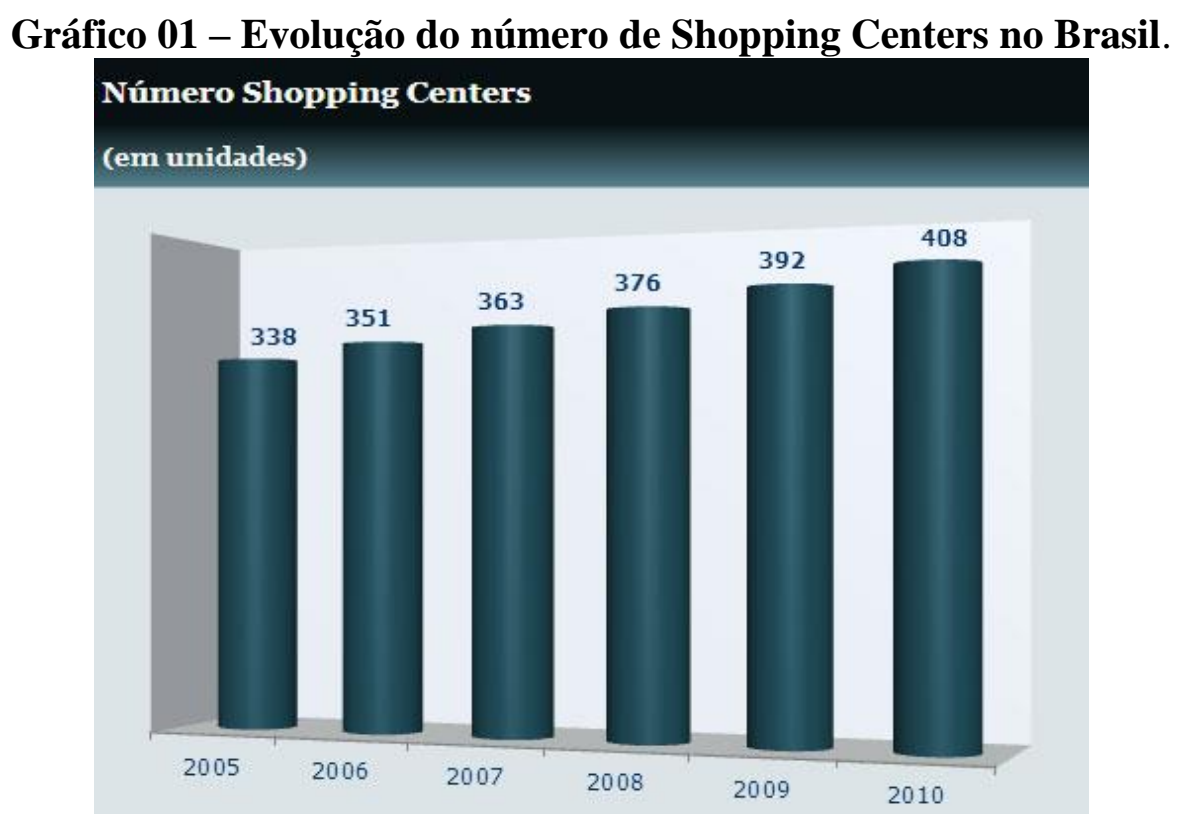

Fonte: ABRASCE, 2011. [http://www.portaldoshopping.com.br] Acesso em 23/06/2011.

Ainda segundo a ABRACE, apesar das inúmeras variações, são basicamente dois tipos de shopping centers existentes: o tradicional, que se divide em quatro tipos de porte -Mega, Regional, Médios e Pequenos - e o especializado, que se divide em três tipos de porte Grandes, Médios e Pequenos -, como mostra abaixoa tabela 01:

Gráfico 02 - Classificação por tipo de Empreendimento.

\begin{tabular}{|c|c|c|c|}
\hline Tipo & Porte & $\mathbf{A B L}$ & Estilo \\
\hline \multirow{5}{*}{ Tradicional } & Mega & Acima de $60.000 \mathrm{~m}^{2}$ & \\
\hline & Regional & De 30.000 a $59.999 \mathrm{~m}^{2}$ & \\
\hline & Médios & De 20.000 a $29.999 \mathrm{~m}^{2}$ & \\
\hline & Pequenos & Até $19.999 \mathrm{~m}^{2}$ & \\
\hline & Grandes & Acima de $20.000 \mathrm{~m}^{2}$ & Outlet \\
\hline \multirow{2}{*}{ Especializado } & Médios & De 10.000 a $19.999 \mathrm{~m}^{2}$ & Temáticos \\
\hline & Pequenos & Até $9.999 \mathrm{~m}^{2}$ & Life Style \\
\hline
\end{tabular}

Fonte: ABRASCE, 2011. [http://www.portaldoshopping.com.br] Acesso em 23/06/2011. 
De acordo com Santos e Silveira, os dados nos chamam a atenção para outro fenômeno relacionado aos shopping centers no Brasil, que é o da interiorização desse tipo de empreendimento cujo melhor exemplo é o estado de São Paulo. No interior paulista, a expansão desses centros de distribuição e consumo ocorre, sobretudo, em cidades de porte médio ${ }^{5}$, ou seja, com populações entre 100 mil e 500 mil habitantes.

Até o final da década de 1990, dos 61 shopping centers existentes, 22 encontravam-se distribuídos em um conjunto de 22 cidades de porte médio. A explicação do fenômeno da interiorização dos shopping centers é dada pelos níveis de renda que no interior do estado são relativamente mais altos do que na Região Metropolitana de São Paulo. (SANTOS e SILVEIRA, 2001, p. 151).

Ao fazer uma análise mais abrangente sobre a localização e a concentração dos shopping centers no território brasileiro, Santos \& Silveira chamam atenção para os seguintes dados:

São 155 shopping-centers no Brasil em 1999. Destes, 61 localizam-se no Estado de São Paulo (39,35\%), 23 no Rio de Janeiro (14, 84\%), dez no Rio grande do Sul $(6,45 \%)$ e oito no Distrito Federal $(5,16 \%)$. A Região Concentrada agrupa, assim, 122 shopping-centers, o que representa 78,71 \% do total do país e 76,32\% do emprego nacional nessas unidades, ainda que este conheça alta sazonalidade. (2001, p. 151).

Sendo assim, percebe-se que a Região Concentrada, além de apresentar o maior número de shopping centers do país, destaca-se pela alta empregabilidade gerada através destes centros de comércio. Os shopping centers concentram-se "no Sudeste do País, que é mais industrializado e urbanizado, e onde vive a maior parte da população brasileira, que detém, inclusive, maior poder de compra." (PINTAUDI, 1992, p. 26).

Ainda segundo Santos \& Silveira (2001, p. 152), a expansão do número de shopping centers no Brasil é um fenômeno recente. Pode-se afirmar que a localização espacial desse tipo de atividade comercial mudou muito nos últimos tempos, assim como aumentou o número de unidades em cidades médias.

Diferentemente da Região Concentrada, outras regiões mais desprovidas de objetos técnicos-informacionais, como é o caso das Regiões Norte e Nordeste brasileiro, apresentam menores números de shopping centers. Escrevem os autores:

\footnotetext{
${ }^{5}$ Utilizamos aqui a expressão cidade de porte médio e não cidade média por se tratar de uma denominação dada apenas pelo número da população.
} 
Nos Estados nordestinos e nortistas, a existência de shopping-centers é, em boa parte um fenômeno da capital ou de Região Metropolitana (Maceió, Salvador, Fortaleza, São Luís, Teresina, Natal, Aracajú, João Pessoa, Recife, Manaus, Belém) (SANTOS e SILVEIRA, 2001, p. 152).

Por outro lado, deve-se levar em conta as especificidades dos estados dessas regiões, para que não se caia no risco das generalizações. No caso dos estados da Paraíba, da Bahia, de Pernambuco e do Rio Grande do Norte, diferentemente de outros estados nordestinos e nortistas, o fenômeno da interiorização dos shopping centers também acontece, porém em menores proporções daquela que existe no estado de São Paulo cuja realidade é muito diferenciada da aqui analisada.

A partir da leitura em Pintaudi (1992, p. 19) acerca dos dados gerais sobre os shopping centers brasileiros, percebemos que, no caso específico do estado da Paraíba, somente no final dos anos 1980 o estado tem o seu primeiro shopping center. Trata-se do Manaíra Shopping Center, inaugurado em outubro de 1989, na capital, João Pessoa.

Sendo assim, a interiorização do shopping center na Paraíba só ocorre mesmo a partir da implantação do Shopping Iguatemi Campina Grande, no ano de 1999. Isso quer dizer que a chegada desse empreendimento comercial no interior do estado só acontece uma década após a inauguração do primeiro shopping center instalado em João Pessoa.

Esse fato foi destacado por Santos \& Silveira (2001, p. 152), ao tratarem da Região Nordeste, especificamente o caso da Paraíba e de Pernambuco: "Na Paraíba existe um shopping-centerem Campina Grande, e em Pernambuco na cidade de Petrolina, ambas as cidades com mais de 100 mil habitantes."

Vale ressaltar que a afirmação dos autores resultou dos dados colhidos para a contagem dos shopping centers no Brasil em 1999. Justo neste ano ocorre, em Campina Grande, a inauguração do "Shopping Iguatemi" que, no final de 2008, passou a se chamar "Boulevard Shopping". Atualmente, o mesmo empreendimento mudou de nome mais uma vez, passando a se chamar "Partage Shopping".

No próximo tópico não trataremos mais da origem ou dadistribuição dos shopping centers no território brasileiro, como acabamos de fazer, mas sim da sua importância enquanto equipamento comercial e de serviços, que, no nosso entender, vem gerando uma reestruturação no espaço de várias cidades, inclusive Campina Grande. Sendo assim, exporemos algumas linhas a respeito dos outros centros comerciais existentes na cidade analisada. 


\section{OUTROS CENTROS COMERCIAIS DE CAMPINA GRANDE}

É fato que a implantação de um shopping center em uma determinada cidade, muitas vezes acompanha a ideia de prosperidade econômica e de elevação do seu status. Antes de Campina Grande possuir um shopping center de fato, há muito tempo que se desejava um projeto do gênero para a cidade, ou algo semelhante, que pelo menos pudesse se chamar de "shopping". Isso pôde ser constatado a partir da análise de registros catologados na imprensa escrita, onde durante quase toda a década de oitenta a elite local perseguiu a ideia de construir um grande shopping center, inclusive iniciando alguns projetos audaciosos, mas que nunca sairam do papel, como veremos adiante.

Dessa forma, o primeiro tipo de empreendimento (ou pelo menos imitação) a ser instalado na cidade foi o "Shopping Campina Grande", localizado na Avenida Floriano Peixoto, no centro da cidade. Esse“"shopping” se caracteriza por ser o primeiro do gênero a ser construído na cidade, ainda no início dos anos 1980, na gestão do então prefeito Enivaldo Ribeiro.O "Shopping Campina Grande”encontra-se localizado no centro da cidade, bem próximo ao Bairro do São João José, que é um dos bairros antigos de Campina Grande (Figura 01).

Figura 01 - Registro aéreo de parte do Centro Tradicional de Campina Grande no início dos anos 1980. No centro da imagem, observa-se o Parque Evaldo Cruz, área conhecida popularmente como "Açude Novo". Na seta amarela, à esquerda, se observa o "Shopping Center Campina", até então, o único empreendimento do gênero na cidade.

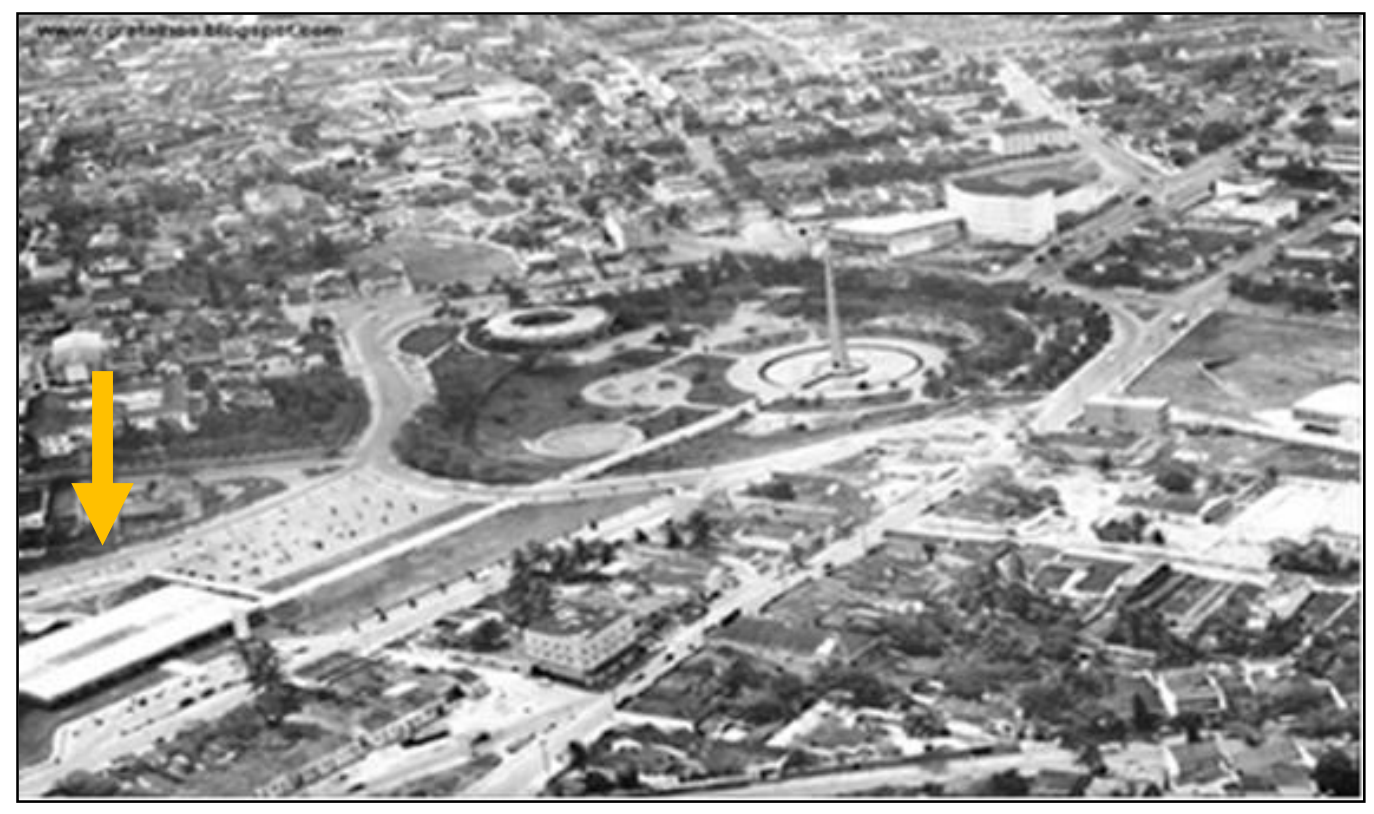

Fonte: www.cgretalhos.blogspot.com [Acesso em 25/03/2010].

Sociedade e Território - Natal. Vol. 28, N. 2, p. 136 - 152. Jun./Dez. de 2016 
De acordo com Costa (2003, p. 66), o primeiro shopping center da cidade foi inaugurado em 1982, construído pela Prefeitura Municipal (Figuras 02 e 03). Na verdade, tratava-se mais de uma galeria, porém se tornou um dos locais mais frequentados de Campina Grande. Mesmo assim, o empreendimento atraiu um grande número de lojas para sua proximidade, como uma “expansão do shopping”, na Avenida Floriano Peixoto:

\begin{abstract}
Vê-se neste objeto geográfico a primeira fase de um processo de descentralização comercial para a cidade. Hoje este shopping encontra-se decadente, o que comprova que o envelhecimento dos lugares é, antes de tudo, envelhecimento ideológico. Nota-se também a efemeridade dos novos sistemas de objetos, pois enquanto o centro da cidade, que fora reconstruído no início da década de 1940, só apresenta sintomas de decadência nos anos 80, portanto, quarenta anos depois. O shopping Center Campina Grande depreciou-se com menos de vinte anos.(COSTA, 2003, p. $66)$.
\end{abstract}

Apesar da existência desse equipamento de consumo, o anseio pela construção de um grande shopping center em Campina Grande parecia ainda persistir. De acordo com Costa (2003, p. 66), "no início dos anos oitenta houve a tentativa de empresários locais para a construção de um grande shopping center no bairro do Alto Branco, projeto que nunca foi concluído, apesar de haver iniciado (timidamente) sua construção".

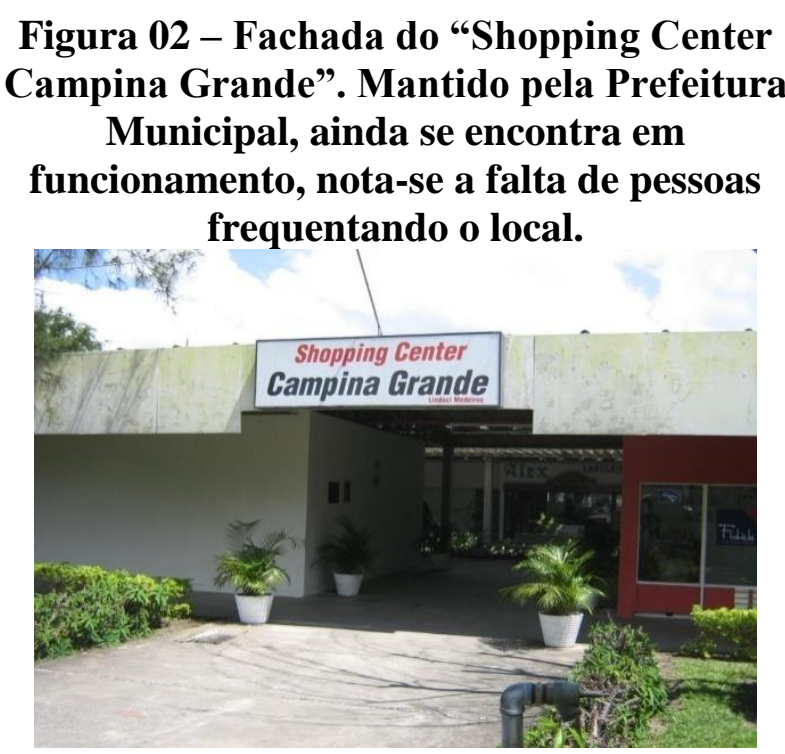

Fonte: Pesquisa de Campo: 28/08/2009.

Foto: Péricles Alves Batista.

\section{Figura 03 - Interior do "Shopping Center Campina Grande", um dos pontos mais frequentados na cidade no inicio da década de 1980.}

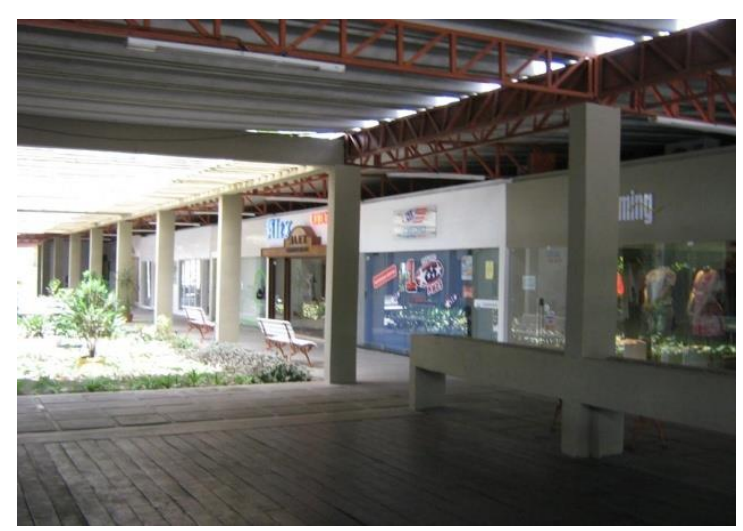

Fonte: Pesquisa de Campo: 28/08/2009

Foto: Péricles Alves Batista.

Além do projeto fracassado de se construir um shopping center no Bairro do Alto Branco, já no final dos anos oitenta, houve outra iniciativa de caráter audacioso de se 
construir um grande shopping center às margens do Açude Velho ${ }^{6}$. Os fragmentos coletados na imprensa escrita da época ${ }^{7}$, que são abaixo indicados, ilustram tal constatação:

Uma equipe da JHM Construções Empreendimentos Ltda., empresa de Nova Friburgo (RJ), esteve, ontem, em Campina grande no gabinete do Prefeito, para a apresentação formalmente de um dos mais arrojados projetos arquitetônicos para a cidade, nos últimos anos [...] O projeto basicamente, trata-se da construção de um "Shopping Center", as margens do Açude Velho.

Terá capacidade para 140 lojas - entre as quais 12 lanchonetes e dois cinemas; um estacionamento subterrâneo, com capacidade para 904 vagas fixas (ou 4.500 vagas/hora); ocupará uma área de $42.745 \mathrm{~m}^{2}$. (Jornal da Paraíba, Campina Grande, Sábado, 16 de Janeiro de 1988).

Essas e outras tentativas passadas de se implantar um shopping center de grandes dimensões em Campina Grande parece ter diminuído com a chegada à cidade de outro empreendimento do gênero, no início dos anos noventa: "o Shopping Luiza Motta". Localizado na RuaVigário Calixto, mais especificamente no Bairro do Catolé, foi o segundo centro comercial de fato a ser construído na cidade da Campina Grande.

O interessante é que, por ser mais afastado do centro da cidade, mesmo havendo no Bairro do Catolé uma intencionalidade por parte do Estado em mudar aquela área, oLuiza Motta parecia prever o despertar econômico do Bairro do Catolé, que, mais tarde, viria a se consolidar enquanto área comercial e de valorização imobiliária em Campina Grande.

Após a sua inauguração, esse centro comercial conseguiu de imediato apresentar um intenso movimento de pessoas. Nessa época, o "Shopping Center Campina Grande” já dava sinais de decadência, de maneira que o "Shopping Luiza Motta" passou a configurar o mais novo point da cidade.

Ainda de acordo com Costa (2003, p. 65), o empreendimento foi inaugurado com o objetivo de "abrigar as lojas das fábricas de confecções existentes em Campina Grande", que foi paulatinamente "acolhendo lojas de grife, e em pouco tempo teve sua área ampliada para atender a este objetivo" (Figuras 04 e 05). Ainda, segundo o autor:

\footnotetext{
${ }^{6} \mathrm{O}$ "Açude Velho", como é popularmente conhecido, foi, na verdade, um dos primeiros reservatórios de abastecimento de água de Campina Grande. Atualmente é mais conhecido por ser um dos principais cartões postais da cidade.
}

${ }^{7}$ JORNAL DA PARAÍBA, Campina Grande, Sábado, 16 de Janeiro de 1988.

Sociedade e Território - Natal. Vol. 28, N. 2, p. 136 - 152. Jun./Dez. de 2016 
[...] em setembro de 1998, empresários e intelectuais campinenses se reuniram na Sede dos Diretores Lojistas para discutir o projeto "Pensando Campina", representantes do Luiza Motta exigiram para esse centro comercial tratamento de "shopping" por parte da prefeitura. Tais lojistas recusavam-se a serem vistos apenas como "comerciantes de lojas de fábricas", argumentando que abrigavam, também, lojas de marcas famosas. Era o momento em que o Iguatemi estava em fase de construção, e certamente os comerciantes locais temiam sua concorrência.

A citação acima mostra a pressão que os comerciantes fizeram para que o empreendimento fosse denominado "shopping center", o que mostra o anseio por figurar algo que representava para a sociedade o moderno, ou o que se tinha nas metrópoles ou nas cidades de maior dinâmica econômica. Os fragmentos coletados na imprensa escrita local da época ${ }^{8}$ expõem já a concretização de tal iniciativa:

\begin{abstract}
Na manhã de ontem, o corpo dirigente do Serviço de Apoio ás Micro e Pequenas Empresas (Sebrae) apresentou à imprensa campinense as obras de ampliação do Shopping Luiza Motta ... [...] Na ocasião Pedro Aurélio Brito, diretor da área de crédito e negócios do Sebrae, apresentou a planta do projeto que está sendo executada e informou que a ampliação dará lugar a doze lojas de grifes famosas [...] O estacionamento será todo calçado e arborizado. "Esta ampliação é positiva porque o Catolé ficará valorizado. Eu acredito que essas casas próximas ao shopping deverão se transformar também em lojas de apoio. [...] Segundo Aurélio, o Shopping Luiza Motta era acusado de não possuir comércio de marcas famosas. As lojas que atualmente comercializam são desta cidade. "O Luiza" vai ter 12 marcas reunidas que nem o nosso futuro concorrente "Iguatemi" terá. Com esta ampliação, eu diria que o shopping está completo", completou.
\end{abstract}

Figura 04 - Aspecto atual do Shopping Luiza Motta após ampliação em 1998. Localizado na RuaVigário Calixto, no Bairro do Catolé.

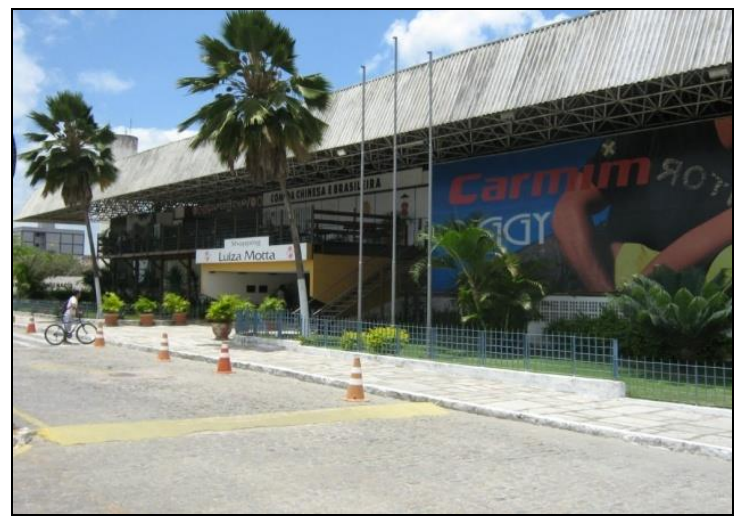

Fonte: Pesquisa de Campo: 28/08/2009.

Foto: Péricles Alves Batista.
Figura 05 - Aspecto atual do Shopping Luiza Motta após ampliação em 1998. Localizado na RuaVigário Calixto, no Bairro do Catolé.

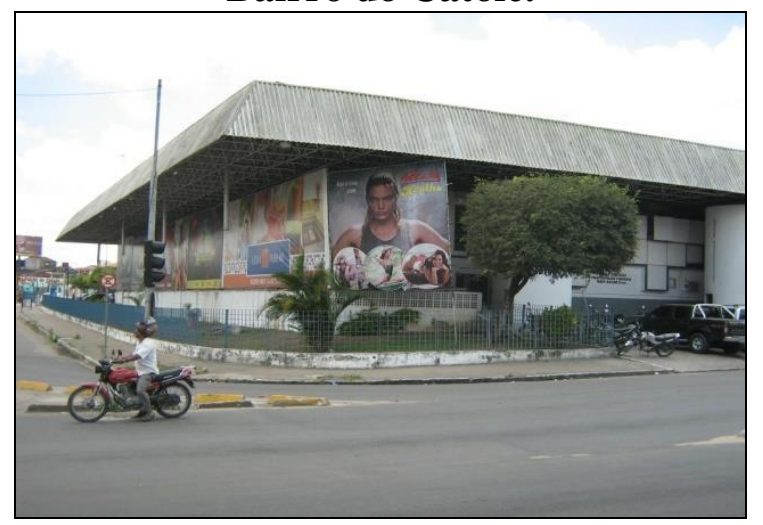

Fonte: Pesquisa de Campo: 28/08/2009.

Foto: Péricles Alves Batista.

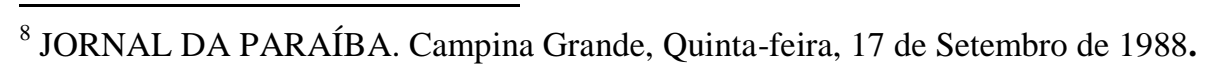

Sociedade e Território - Natal. Vol. 28, N. 2, p. 136 - 152. Jun./Dez. de 2016 
No final da década de 1990, inaugura-se, também no Bairro do Catolé, o mais novo e maior empreendimento comercial da cidade, o único que até então poderia ser considerado, segundo os critérios da ABRASCE, dentro dos atuais padrões de shopping center: o Shopping Iguatemi, que mais tarde passaria a se chamar Boulevard Shopping e posteriormente Partage Shopping. É interessante, ainda, analisar na época de sua inauguração o discurso da impresa local $^{9}$, em relação à chegada desse empreendimento comercial na cidade:

Ousada e destemida, Campina Grande definitivamente entra na era dos shopping centeres. [...] Representando um verdadeiro divisor de águas o Iguatemi chega exatamente quando a cidade mais precisava. Ele atende aos anseios de um povo destemido, que não se intimida com crise e que tem, agora, uma nova perspectiva do desenvolvimento, fazendo com que os sonhos de um novo tempo - baseado no progresso e na geração de emprego e renda - fiquem mais próximos.

Sobre esse fato, Costa (2003, p. 65) afirma que no "ano de 1991, já havia sido construído o Shopping Luiza Motta, também no Bairro do Catolé, porém, por se tratar de um shopping de fábrica, não teve o mesmo 'glamour' que o Shopping Iguatemi'. O autor comenta que, por se situarem relativamente próximos, "os dois shoppings contam com uma linha de ônibus que faz a ligação entre ambos" (Ibidem, p. 66). As vias que ligam o Boulevard Shopping ao Shopping Luiza Motta são as ruas Raimundo Nonato e João Quirino no Catolé.

Com a construção do Shopping Iguatemi, chegou-se a pensar que o Shopping Luiza Motta, mesmo após a sua ampliação, iria entrar em decadência em pouco tempo, por não ter condições de competir diretamente com o Iguatemi. "O Iguatemi estava em fase de construção, e certamente os comerciantes temiam sua concorrência” (COSTA, 2003, p. 66). Esse temor foi desconstruído assim que os dois empreendimentos começaram a funcionar ao mesmo tempo, “o que 'pôs por terra' o receio de que a cidade não comportaria o shopping Iguatemi" (ibidem).

Nesse sentido, de acordo com Cardoso \& Maia (2007, p. 536), “[...] consideramos a cidade de Campina Grande com alguns índices de modernização, como por exemplo, [...] a construção de shoppings [...] a cidade conserva uma necessidade de estar sempre reafirmando a sua modernidade $[\ldots] "$.

Chama-nos a atenção, ainda, atualmente, na cidade de Campina Grande, outros centros menores de comércio existentes, que, apesar de seu pequeno porte, na maioria das vezes acabaram ganhando a denominação de "shopping center”. Na verdade, alguns desses pequenos

\footnotetext{
${ }^{9}$ JORNAL DA PARAIBA. Seja bem vindo, Iguatemi. Campina Grande, Quinta-feira, 29 de Abril de 1999. Caderno Cidades, p.09.
} 
centros de comércio poderiam muito bem ser classificados como galerias e não propriamente shopping centers.

Pelo termo, no que representa o "moderno", com o intuito de elevar o status comercial, é que pequenas galerias comerciais passaram a ser denominadas deshopping centers.É o caso do "Shopping Cirne Center" (Figuras 06 e 07), que se encontra na Rua Afonso Campos, no centro da cidade e o "Babilônia Center", situado na Rua Irineu Joffily, também no centro de Campina Grande (Figura 08). O primeiro, após reformas sucessivas, passou a ser denominado de "shopping center", enquanto o segundo, inaugurado em 2007, tratava-se originalmente do tradicional Cinema Babilônia, que fechou no ano de 2000. Além desses pequenos dois centros comerciais, há outra galeria no centro da cidade chamada "Maanaim Center" (Figura 09), considerado um "shopping" de atacado. Esse empreendimento e o "Shopping Campina Grande" têm as mesmas características de comércio de vestuário atacadista e localizam-se na mesma área.

Figura 06 - Shopping Cirne Center, localizado no centro de Campina Grande.

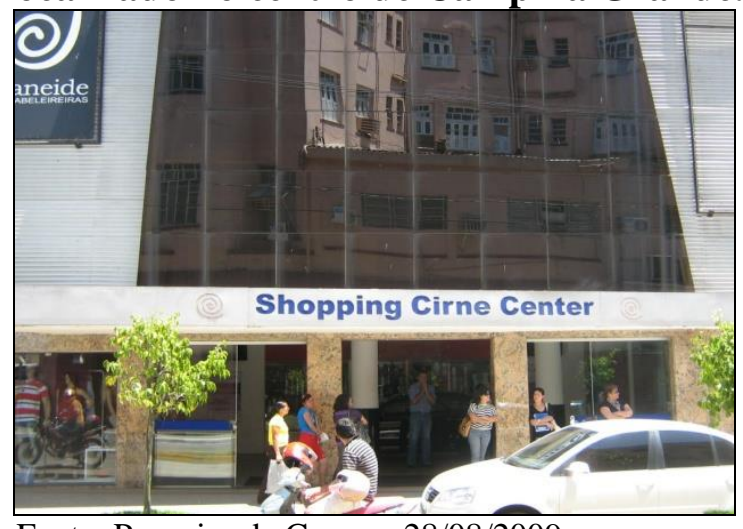

Fonte: Pesquisa de Campo: 28/08/2009

Foto: Péricles Alves Batista.
Figura 07 - Shopping Cirne Center, localizado no centro de Campina Grande.

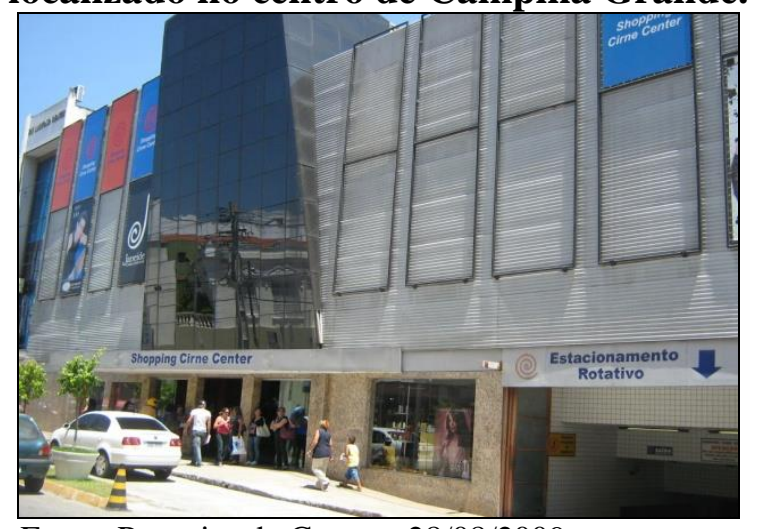

Fonte: Pesquisa de Campo: 28/08/2009 Foto: Péricles Alves Batista.

Todos esses espaços são de consumo reúnem desde o comércio informal (como é o caso do camelódromo "Shopping Edson Diniz) até o comércio formal propriamente dito. Outros centros de comércio, porém, se especializaram na venda a atacado, enquanto que a maioria comercializa no varejo. A realidade é que a maioria desses pequenos centros de comércio poderia muito bem ser classificados como galerias. Independentemente da característica comercial, o fato é que todos se utilizam das denominações de "shopping" ou"center", para atrair um maior público e configurar-se como uma novidade ou algo moderno na cidade. 
Figura 08 - Prédio do antigo Cine Babilônia, atualmente transformado em "BabilôniaCenter".

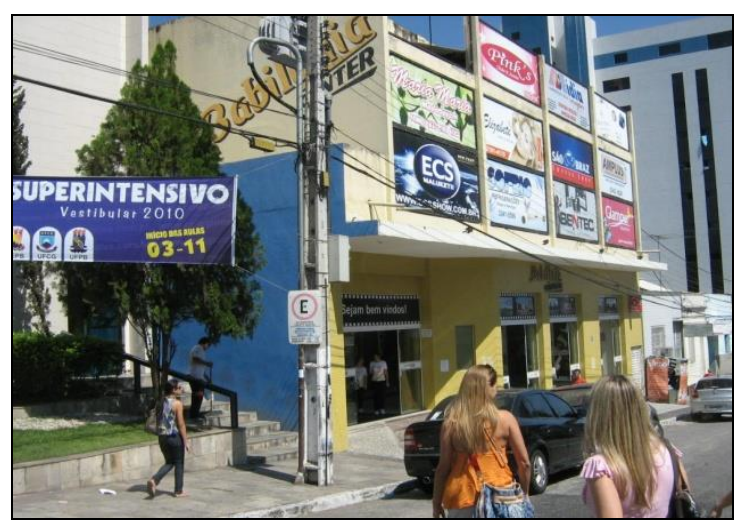

Fonte: Pesquisa de Campo: 28/08/2009. Foto: Péricles Alves Batista.
Figura 09 - Maanaim Center, localizado no centro da cidade, em frente ao "Açude Novo" e por trás do Teatro Severino

Cabral.

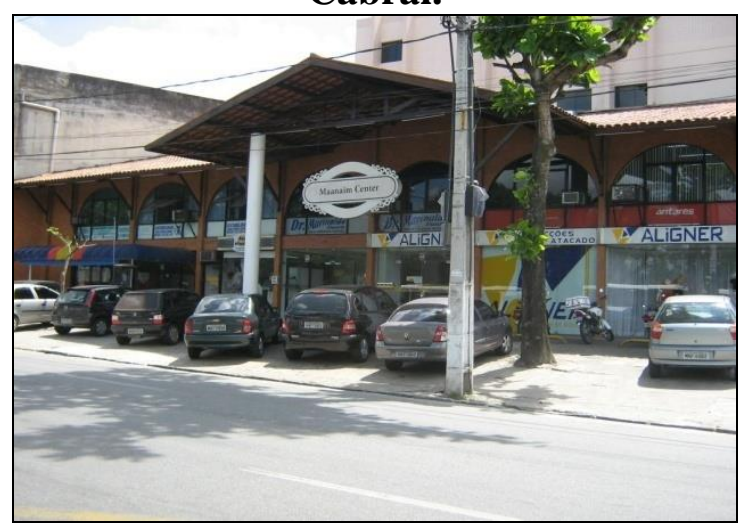

Fonte: Pesquisa de Campo: 24/12/2009.

Foto: Péricles Alves Batista.

A partir da ascensão do setor terciário na economia campinense na última década, começa-se a perceber um processo lento de descentralização do comércio local em Campina Grande. Nesse sentido, sua área central vem apresentando indícios de um processo lento de descentralização via novas áreas periféricas. Isso não quer dizer que o centro deixou de exercer influência para o restante dos bairros, bem como para dezenas de pequenas cidades localizadas na sua área de influência. Pelo contrário, inclusive, em alguns tipos de atividades econômicas, essa área central apresenta a concentração de variados tipos de fluxos, até mais importantes do que antes do processo de descentralização comercial.

Isso nos leva a afirmar que o processo de descentralização das atividades comerciais na cidade em questão, ocorre agora através de um processo de reestruturação urbana, representado pela descentralização de algumas atividades comerciais no centro tradicional, impulsionadas agora pela expansão da cidade na direção leste, em consonância com a direção da localização do Partage Shopping.

\section{CONSIDERAÇÕES FINAIS}

A partir da discussão realizada sobre os centros de comércio de Campina Grande, percebe-se que nos últimos anos, a sua área central vem apresentando indícios de um processo lento de reorganização e até mesmo de descentralização de alguns empreendimentos 
comerciais. Como foi abordado através da questão da formação e constituição de algumas dessas galerias de comércio, denominadas propositadamente de "shoppings".

Não obstante, é bom que se diga que a cidade ainda apresenta um centro que exerce forte influência para o restante dos bairros, bem como para dezenas de pequenas cidades localizadas na sua área de influência. Inclusive, por outro lado, em alguns tipos de atividades comerciais, essa área central apresenta a concentração de variados tipos de fluxos até mais importantes do que antes do ínicio do processo de descentralização pelo qual o centro de Campina Grande passa.

Isso nos leva a afirmar que esse processo de descentralização ocorrido na referida Área Central, apresenta uma continuidade cada vez mais evidente, mas, contraditoriamente, ao mesmo tempo, reforça-se a sua centralidade. Sendo assim, observa-se em Campina Grande um verdadeiro processo de reestruturação urbana, representado pelo deslocamento de algumas atividades comerciais do Centro, impulsionadas pela expansão da cidade na direção leste, em consonância com a direção da localização do shopping center dessa cidade.

Em face do exposto, a importância em estudar a ascensão do setor terciário na economia local, dá-se pela necessidade de entender a formação de uma nova centralidade a partir das tentativas de implantação dos centros comerciais, como foi abordado. Nesse contexto, espera-se que este estudo possa contribuir para o entendimento de algumas questões urbanas, principalmente o processo de reestruturação e descentralização do espaço campinense, durante a última década.

\section{REFERÊNCIAS}

ABRASCE - Associação Brasileira dos Shopping Centers. Evolução do número de Shopping Centers no Brasil. Disponível em: [http://www.portaldoshopping.com.br] Acessado em 23/06/2011.

.Disponível em: http://www.portaldoshopping.com.br/monitoramento/numeros-dosetor. Números do setor. Acessado em 30/08/2016.

CARDOSO, Carlos Augusto de. \&MAIA, Doralice. S. Das feiras às festas: as cidades médias do interior do nordeste . In: In: SPOSITO, Maria da Encarnação Beltrão. (org.). Cidades Médias: Espaços em transição.São Paulo: Expressão Popular, 2007. p. 517 - 550.

CARLOS, Ana Fani. A forma da cidade. In: CARLOS, Ana Fani. Espaço - Tempo na Metrópole. São Paulo: Contexto, 2001; pp. 45 - 84. 
COSTA, Antônio Albuquerque. Sucessões e Coexistências do Espaço Campinense na sua Inserção ao Meio Técnico-Científico-Informacional: a feira de Campina Grande na interface desse processo. Dissertação de Mestrado do Departamento de Ciências Geográficas da UFPE: Recife, 2003.

HIRSCHFELDT, Roberto Vladimir. SHOPPING CENTER - O templo do Consumo. Rio de Janeiro: ABRASCE, 1986.

JORNAL DA PARAÍBA, Campina Grande, Sábado, 16 de Janeiro de 1988.

JORNAL DA PARAIBA. Seja bem vindo, Iguatemi. Campina Grande, Quinta - feira, 29 de Abril de 1999. Caderno Cidades, p.09.

MEYER, Regina Maria Prosperi. O papel da rua na urbanização paulistana. Cadernos de História de São Paulo: A cidade e a rua, São Paulo, Museu Paulista da Universidade de São Paulo, n. 2, p. 13-26, janeiro-dezembro 1993.

PADILHA, Valquíria. SHOPPING CENTER a catedral das mercadorias. São Paulo: Boitempo, 2006.

PINTAUDI, Silvana Maria. O shopping centers no Brasil: condições de surgimento e estratégias de localização. In: PINTAUDI, Silvana Maria e FRÚGOLI Jr., Heitor (orgs): Shopping centers: espaço, cultura e modernidade nas cidades brasileiras. São Paulo: Editora UNESP, 1992.

.O Templo da Mercadoria - estudo sobre os Shopping-Centers do Estado de São Paulo. Tese (Doutorado em Geografia Humana)- Universidade de São Paulo: São Paulo, 1989.

A cidade e as formas comércio. In: CARLOS, Ana Fani A. (org.) Novos Caminhos da Geografia. São Paulo: Contexto, 1999. p.143-159.

SANTOS, Milton \& SILVEIRA, María Laura. O Brasil: território e sociedade no início do século XXI. Rio de Janeiro: Record, 2001.

SOUZA, Marcelo Lopes de. ABC do Desenvolvimento Urbano. Rio de Janeiro: Bertrand, 2003.

VILLAÇA, Flávio. Espaço intra-urbano no Brasil. São Paulo: Studio Nobel, 1998.

Recebido em Agosto de 2016

Aprovado em Dezembro de 2016

Publicado em Dezembro de 2016

Sociedade e Território - Natal. Vol. 28, N. 2, p. 136 - 152. Jun./Dez. de 2016 